\title{
LA GEOGRAFÍA EN LA REVISTA DE ESCUELAS NORMALES (1923-1936).
}

POR

\author{
CLEMENTE HERRERO FABREGAT
}

\section{Introducción}

La Revista de Escuelas Normales apareció en enero de 1923 en un ambiente de descomposición del sistema de la Restauración que daría lugar al golpe de Estado del General Primo de Rivera en septiembre de ese mismo año. El último número corresponde a mayo de 1936 (núm. 120) en pleno desmoronamiento del sistema democrático liberal de corta existencia en la vida política española. Paradójicamente en un momento de crisis política del sistema se dio un período de apogeo cultural sin precedentes desde el Siglo de Oro plamado a nivel educativo en la aparición de una serie de publicaciones. Como indica Mérida-Nicolich (1983), que ha estudiado en profundidad otra de las publicaciones pedagógicas, estas revistas responden básicamente al ambiente regeneracionista de la época, muy preocupado por los temas educativos. Entre 1915 y 1923 aparecen los Cuaderns d'Estudi (Barcelona, 1915), siendo 1922 un año crucial para los temas educativos ya que se inicia la publicación de la Revista de Pedagogía, el Boletín de la federación de maestros nacionales de Cataluña y el Bulleti dels mestres, como publicación quincenal de la Mancomunidad. De todas ellas es la Revista de Escuelas Normales la que dio mayor cabida a la Geografía, dándose a 
conocer a través de sus páginas los principios científicos que la sustentan. Profesores de las Escuelas Normales, junto con algunos profesores de Institutos de Segunda Enseñanza, fueron los que introdujeron y desarrollaron la nueva ciencia geográfica en los ambientes educativos.

Pedro Chico, Miguel Santaló, Isidoro Reverte, Rodolfo Llopis introdujeron las bases de la moderna Geografía mediante los artículos publicados en esta revista, que se constituyó en una plataforma en la que se expusieron los avances científicos y educativos a una sociedad que estaba ilusionada con un cambio profundo, en el que la educación era un factor fundamental. Gracias a la presencia activa de un grupo de geógrafos formados en la Escuela Superior de Estudios del Magisterio, se inició este proceso en el que colaboraron también algunos profesores de Enseñanza Media, como Juan Carandell. En un corto período de tiempo, menos de catorce años, se dieron a conocer en España a través de esta publicación las teorías más actuales del momento, tales como la de los ciclos de erosión de Davis, los criterios para establecer análisis de tipo locacional, las nuevas teorías geopolíticas, la Geografía de las calamidades, y sobre todo se introdujeron los criterios para definir la Geografía regional, todo ello acompañado de una serie de propuestas educativas basadas en modernas teorías pedagógicas, muy influidas por el ambiente institucionista y regeneracionista de la época.

Todas estas innovaciones quedaron cortadas de raíz con la guerra civil en el ámbito de las Escuelas Normales, que iniciaron una decadencia, mientras que en las Universidades se inició un gran desarrollo científico de la Geografía a partir de la década de los cuarenta y principio de los cincuenta. «El acceso a las cátedras universitarias de los profesores José Manuel Casas Torres y Manuel Terán Álvarez dio origen a los dos grandes grupos de geógrafos universitarios en la historia reciente de España. Los profesores Casas Torres y Terán son sin discusión los dos grandes maestros de la geografía española actual» (Capel, 1976, p. 13). Se establecen desde ese momento dos círculos científicos, uno en la Universidad de Zaragoza y otro en la Complutense de Madrid, con sus posteriores ramificaciones. 


\section{Características de la Revista de Escuelas Normales}

La Revista de Escuelas Normales fue el órgano de la Asociación Nacional del Profesorado Numerario de esos centros, aunque anteriormente a 1923 existió un Boletín de Escuelas Normales que se editó durante el año 1922 en la Escuela Normal de Guadalajara. Su formato fue de 16,5 por 24,5 , y tuvo una portada permanente a lo largo de catorce años. Su periodicidad era mensual, salvo los meses de verano. Se sufragaba con las cuotas de los asociados y con lo que se obtenía de unas páginas dedicadas a la publicidad.

Se trata de una publicación itinerante ya que su consejo editorial estuvo radicado en las Escuelas de Guadalajara (enero de 1923 a noviembre de 1927, y posteriormente de junio de 1931 a diciembre de 1932), Cuenca (diciembre de 1927 a noviembre de 1929), Córdoba (diciembre de 1929 a mayo de 1931) y Madrid (enero de 1933 a junio de 1936). Los talleres de impresión fueron Gutemberg en Guadalajara, Talleres tipográficos Velasco en Cuenca, en Córdoba, e Imprenta Juan Pueyo en Madrid ${ }^{1}$. Los directores fueron Modesto Bargalló, Rodolfo Llopis, Antonio Gil Muñiz, de nuevo Bargalló y grupo de profesores en su última etapa madrileña.

En sus secciones hay que destacar dos núcleos centrales: «Ciencia y educación» y «La Normal en acción». Ambas ocuparon en su trayectoria el 36,8 \% de sus páginas. El resto - «libros y revistas», de recensión bibliográfica especializada, «Páginas pedagógicas», «Prensa y noticias», «Societarias»- tiene una distribución equiparable. En el curso de la publicación aparecen otras secciones como «Nuestros maestros», «Clásicos y modernos de la Pedagogía», «Nuestras confe-

\footnotetext{
1 La revista presenta algunos problemas, como el de la numeración y paginación. Después del número 58, correspondiente a diciembre de 1928, se inicia una nueva numeración para el año 1929: $1,2 \ldots, 20$, que se corresponden con los números generales: $59,60,61,62,63,64,65,66,67,68$. El número 20 corresponde a diciembre de 1929 , debiendo tratarse de un error, es el 10 de este período, ya que la numeración de las páginas se continúa normalmente. Se ha seguido la numeración general poniendo entre paréntesis las correspondientes a 1929. Además se observan cambios de numeración en las páginas en los números 83 y 91 correspondiente a octubre de 1931 y diciembre de 1932 .

Se han analizado los fondos de las siguientes bibliotecas: Hemeroteca Municipal de Madrid, Escuela Universitaria del Profesorado de Guadalajara, Nacional, Museo de Ciencias Naturales, Pedagogía (CSIC) y Universitaria de Valencia.
} 
rencias», «La formación del Magisterio», «Reformas pedagógicas», «Reforma de las Normales», «Crónicas del extranjero», «Nueva educación», «Nueva didáctica», etc. En todas ellas «se desarrolló una línea temática continua de doble vertiente: la actualización científica dirigida a la profundización didáctica, planteada desde los problemas de la enseñanza. Por ello la revista incluyó artículos dedicados a la divulgación de temas científicos, culturales o artísticos y, especialmente, al tratamiento metodológico de estos temas, a sus implicaciones didácticas en el magisterio, lo mismo que al estudio de aspectos pedagógicos nuevos» (Díez, Pozo, Segura, 1987, p. 20).

Para el estudio de la Geografía en esta revista se ha agrupado el material en:

a) Artículos, divididos en dos grupos. Unos de carácter científico corresponden básicamente a la sección «Educación y enseñanza» y «Ciencias y educación». Otros didáctivos, fundamentalmente de la sección «La Normal en acción».

b) Recensiones obtenidas de la sección «Libros y revistas», sirven para conocer el consumo bibliográfico de los profesores de Geografía de estos centros.

Para un mejor análisis y clasificación de todo este material se han establecido tres bases de datos. Dos dedicadas cada una a todos los artículos y recensiones publicadas en la revista. Cada registro constaba de los siguientes campos: autor, título, año romano, año natural, mes, número, páginas, ilustraciones, secciones, área de procedencia, área lingüística, cuatro descriptores para la materia, y para los artículos dos registros más, número de referencias bibliográficas y tipo de referencias (mención o referencia propiamente dicha).

Una tercera base se ha dedicado para analizar las menciones y referencias bibliográficas de los artículos geográficos. Cada registro constaba de los siguientes campos: mencionado, área de conocimiento a la que pertenece, mencionador, año, número de la revista, páginas, tipo de referencia (mención o referencia propiamente dicha) área de procedencia, área lingüística, tipo de artículo, y cuatro campos para la materia y su desglose. 
Para la interpretación de todos estos datos se han utilizado algunos conceptos propios de los análisis bibliométricos, pero no se trata de un estudio bibliométrico en sí debido al corto espacio de la publicación, no llega a catorce años y 120 números, y a sus características. Por esta razón conceptos como crecimiento exponencial y curva logística, obsolescencia de la ciencia, ecuación de regresión, dispersión de la literatura científica (Bradford), etc., no son de aplicación a este trabajo. Únicamente se ha seguido alguna orientación bibliométrica en el estudio de las referencias bibliográficas para analizar las influencias en la producción geográfica, así como en el análisis de la productividad por autores. Pero los resultados obtenidos tienen que validarse con el análisis conceptual que se realiza posteriormente.

\section{Producción geográfica en relación con otras disciplinas}

En el estudio de la producción tanto general como geográfica se han incluido, además de los artículos, las recensiones bibliográficas, ya que ellas permiten conocer las influencias educativas, científicas y geográficas que se daban en esta comunidad de docentes e investigadores. Estas últimas están muy actualizadas, reseñándose los libros prácticamente en el mismo año de su publicación, además, como se podrá observar más adelante, un porcentaje de las mismas está dedicado a obras publicadas en el extranjero en las propias lenguas vernáculas.

Se publicaron 637 artículos de los que 102 corresponden a Geografía. El promedio de páginas es de 3,5 y en ellos se incluyen, salvo en dos grupos de artículos didácticos, una serie de referencias y menciones bibliográficas. De las 653 recensiones publicadas 130 correspondían a Geografía, ocupando menos de una página cada una. Tanto en los artículos (cuadro I) como en las reseñas, la Geografía ocupa el segundo lugar dentro de la producción científica de la revista, posiblemente por el enfoque de la misma ya que facilitaba el conocimiento de la realidad de España para desde el mismo intentar una regeneración y un cambio de la realidad social y económica de la nación.

$$
-35-
$$


Cuadro I

PRODUCCIÓN GEOGRÁFICA (ARTÍCULOS) EN RELACIÓN CON EL RESTO DE LAS MATERIAS

\begin{tabular}{lcr} 
Área temática & Núm. artículos & \multicolumn{1}{c}{ \% } \\
\hline Educación & 311 & 48,8 \\
Geografía & 102 & 16,0 \\
Física y Química & 54 & 8,5 \\
Matemáticas & 41 & 6,4 \\
Lengua y literatura & 39 & 6,1 \\
Filosofía & 25 & 3,9 \\
Ciencias naturales & 16 & 2,5 \\
Historia & 17 & 2,7 \\
Otras & 32 & 5,0
\end{tabular}

El impulso dado a la Geografía como disciplina propició su separación de la Historia en las Escuelas Normales y su mayor peso en la reforma de los estudios de Magisterio llevada a cabo por Eloy Bullón, Director General de Enseñanza Primaria y catedrático de Geografía de la Universidad Central de Madrid, que se plasmó en el plan de estudios de 1914. El centro de toda esta renovación geográfica y pedagógica hay que situarlo en la Escuela de Estudios Superiores del Magisterio (1909-1932) en la que profesores como Ricardo Beltrán y Rózpide y Luis de Hoyos Sainz iniciaron un proceso de actualización geográfico-pedagógica cortado a raíz de la guerra civil. Por esto «es imposible hacer la historia de la renovación de la Geografía (o de la Pedagogía), como disciplina y como ciencia, en la España de la preguerra, sin aludir al papel relevante desempeñado por la Escuela de Estudios Superiores del Magisterio, muy influida en su concepción educativa y geográfica por la Institución Libre de Enseñanza» (Molero, 199 , p. 163).

Este peso de la Geografía se observa también en las recensiones bibliográficas donde sigue ocupando el segundo lugar, después de los temas pedagógico-educativos (cuadro II).

Se reseñan obras de otro tipo, pero siempre desde una temática de renovación y regeneración de la cultura española en la que la labor de la escuela es fundamental para alcanzar cotas de mayor libertad y justicia. Importante es el porcentaje de libros de todas las ma- 
Cuadro II

NÚMERO DE RESEÑAS GEOGRÁFICAS EN RELACIÓN CON EL RESTO

DE LAS MATERIAS

\begin{tabular}{lcr} 
Área temática & Núm. reseñas & \multicolumn{1}{c}{ \% } \\
\hline Educación & 252 & 38,6 \\
Geografía & 130 & 19,9 \\
Lengua y Literatura & 62 & 9,5 \\
Física y Química & 44 & 6,7 \\
Historia & 39 & 6,0 \\
Ciencias Naturales & 38 & 5,8 \\
Matemáticas & 28 & 4,3 \\
Psicología & 16 & 2,4 \\
Filosofía & 12 & 1,8 \\
Arte & 10 & 1,5 \\
Otras & 22 & 3,4
\end{tabular}

terias recensionados en su propia lengua, que suponen un $12 \%$ del total. Los libros geográficos suponen un $19,7 \%$ de toda las recensiones realizadas en la revista.

\section{Distribución de la producción geográfica}

Dado el carácter eminentemente profesional de la revista, los artículos son de dos tipos, unos científicos (48) y otros que presentan una serie de alternativas didácticas (54). Estos últimos están fundamentados en las modernas teorias educativas, en ellas se utiliza el método topográfico basado en la observación y experimentación de lo inmediato para comprender posteriormente lo lejano, es el que se utiliza, tal como se deduce del título de los artículos.

En los artículos científicos se da una buena distribución de los temas que se desarrollan, oscilan entre un 16,6 \% los de Geografía rural hasta un $2 \%$ los de Oceanografía. Hay un grupo en el que se define el concepto de Geografía con artículos verdaderamente valiosos como el de Santaló (1929). Otros dos grupos temáticos que destacan por lo novedoso del tema son el de la «Geografía de las calamidades» y el de «Geopolítica» (cuadro III). 
DISTRIBUCIÓN DE LOS ARTÍCULOS CIENTÍFICOS DE GEOGRAFÍA SEGÚN SU TEMÁTICA

\begin{tabular}{lcc} 
Tema & Número & \% \\
\hline Geografía rural & 8 & 16,7 \\
Cartografía & 6 & 12,5 \\
Geografía regional & 6 & 12,5 \\
Geomorfología & 6 & 12,5 \\
Geopolítica & 5 & 10,4 \\
Concepto & 4 & 8,3 \\
Geografía de las calamidades & 4 & 8,3 \\
Congresos & 3 & 6,2 \\
Geógrafos & 3 & 6,2 \\
Viajes & 2 & 4,2 \\
Oceanografía & 1 & 2,1
\end{tabular}

Los artículos dedicados a la Didáctica de la Geografía se han reunido en tres grupos, uno dedicado a la fundamentación didáctica y actualización científica, que se denomina Teoría educativa y actualización científica, otro a exponer una serie de sugerencias, y un tercer grupo, el más importante porcentualmente que se dedica al excursionismo geográfico-pedagógico (cuadro IV).

CuAdro IV

DISTRIBUCIÓN DE LOS ARTÍCULOS DIDÁCTICOS SEGÚN SU TEMÁTICA

\begin{tabular}{lcc} 
Tema & Número & $\%$ \\
\hline Excursiones & 23 & 42,5 \\
Sugerencias didácticas & 17 & 31,5 \\
Teoría educativa y actualización científica & 14 & 26,0
\end{tabular}

Como se observa, el excursionismo ocupa cerca de la mitad de los artículos didácticos, ya que esta práctica escolar se va a constituir como un pilar fundamental en una pedagogía basada en la observación, comprensión y amor de la naturaleza, con una fuerte carga ecológica y cultural. 
La distribución temática de las recensiones publicadas, que sirve para conocer el consumo bibliográfico del colectivo de docentes de estos centros, abarca prácticamente toda la temática de la Geografía (cuadro V).

Cuadro V

DISTRIBUCIÓN DE LAS RESEÑAS DE GEOGRAFÍA SEGÚN SU TEMÁTICA

\begin{tabular}{lcclcr} 
Tema & Número & \% & Tema & Número & \% \\
\hline Regional & 37 & 28,5 & Hidrografía & 2 & 1,5 \\
Didáctica & 23 & 17,7 & Biogeografía & 1 & 0,7 \\
General & 15 & 11,5 & Calamidades & 1 & 0,7 \\
Geomorfología & 9 & 6,9 & Circulación & 1 & 0,7 \\
Concepto & 5 & 3,8 & Climatología & 1, & 0,7 \\
Oceanografía & 5 & 3,8 & Congresos & 1 & 0,7 \\
Rural & 5 & 3,8 & Demografía & 1 & 0,7 \\
Astronómica & 4 & 3,1 & Geopolítica & 1 & 0,7 \\
Histórica & 4 & 3,1 & Rural & 1 & 0,7 \\
Viajes & 4 & 3,1 & Suelos & 1 & 0,7 \\
Geógrafos & 3 & 2,3 & Turismo & 1 & 0,7 \\
Cartografía & 3 & 2,3 & Urbana & 1 & 0,7
\end{tabular}

Destacan en los tres primeros lugares los libros reseñados de Geografía regional, Didáctica y Geografía general, con un 28,7\%, $17,8 \%$ y $11,6 \%$, seguidos de un grupo constituido por Geomorfología, aspectos conceptuales, Oceanografía, Geografía rural, histórica, astronómica y viajes.

Estos libros reseñados tienen la siguiente distribución por áreas de procedencia: 104 corresponde a autores españoles, nueve a geógrafos franceses y otros nueve a portugueses, dos respectivamente a alemanes, ingleses y latinoamericanos y uno a Canadá y otro a Estados Unidos. Por tanto un $80 \%$ de las reseñas publicadas son de geógrafos españoles. No obstante, es de destacar que se reseñan una serie de libros no traducidos al castellano, en total 15, con la siguiente distribución: seis en portugués, tres en francés, tres en catalán, dos en inglés y uno en alemán. Este último es un tratado de climatología de Hann publicado en Sttutgart en 1932 y dado a conocer en España al año siguiente, Handbuch der Klimatologie. A primera vista 
estos resultados pueden dar a entender que existían pocas influencias exteriores, pero el análisis de las referencias bibliográficas demostrará lo contrario.

\section{Productividad por autores}

Tanto en los 102 artículos publicados de Geografía como en las 130 recenciones bibliográficas se observa una tendencia a que un número muy pequeño de autores publiquen un elevado número de artículos o recensiones. Este hecho puede acercar al concepto de productividad que se utiliza en Bibliometría aplicado por Lotka en 1926, de acuerdo con el cual el número de autores que publican $n$ trabajos es inversamente proporcional a $n^{2}$, pero como el tiempo que se cubre es relativamente reducido, no es aplicable por lo que se enumeran únicamente los autores, con el número y percentaje de artículos (cuadro VI).

\section{CuAdro VI}

AUTORES MÁS PRODUCTIVOS

\begin{tabular}{lrr} 
Autor & Número de artículos & \% \\
\hline Chico, Pedro & 25 & 24,5 \\
Carandell, Juan & 8 & 7,8 \\
Reverte, Isidoro & 7 & 6,9 \\
Santaló, Miguel & 7 & 6,9 \\
Muñiz, Benigno & 4 & 3,9 \\
Beltrán y Rózpide, Ricardo & 3 & 2,9 \\
Francés, R. & 3 & 2,9 \\
Hernández-Pacheco, Francisco & 3 & 2,9 \\
Jiménez, M. ${ }^{\text {a Victoria }}$ & 3 & 2,9 \\
Llopis, Rodolfo & 3 & 2,9 \\
Bargalló, Modesto & 2 & 2,0 \\
Antón Cano, Luis & 2 & 2,0 \\
Barcia Trelles, Camilo & 2 & 2,0 \\
Ortega, Felipe & 2 & 2,0 \\
Recasens, Dr. & 2 & 2,0 \\
Roselló, P. & 2 & 2,0 \\
Saiz Salvat, F. & 2 & 2,0 \\
22 autores con un artículo & 22 & 21,6
\end{tabular}


El autor más productivo es Pedro Chico, con un 24,5\% de los artículos publicados, en el otro extremo hay un grupo de 22 autores que significan globalmente un $21,6 \%$ e individualmente un $0,98 \%$. Respecto a las reseñas también se da una concentración en la productividad, Pedro Chico escribe 59 que suponen un 45,5\% del total, seguido Miguel Santaló, 13 (10\%); M. B. 2, 9 (6,9\%); Rodolfo Llopis, 8 (6,1\%), y Modesto Bargalló, 7 (5,4\%), el 17,2 \% se reparte entre 22 autores que tienen entre una y cuatro reseñas, lo que supone una media $0,78 \%$. Estos porcentajes de productividad hay que matizarlos según las diferentes áreas temáticas.

En el grupo de artículos que definen el concepto de Geografía Felipe Ortega escribió dos, seguido de Miguel Santaló y Luis Antón Cano con uno por autor.

Francisco Hernández-Pacheco es el que mayor aportación hace en el grupo de cartografía con tres artículos dedicados al mapa topográfico 1:50.000 que publica simultáneamente en esta revista y en el Boletín de la Sociedad Geográfica Nacional entre 1935 y 1936. Analiza las hojas de Quintanar de la Sierra, Burgos-Soria (349); Aoiz, Navarra (142); Santo Domingo de Silos, Burgos (315); Ponferrada, León (158), y Verges, Gerona (296).

En Geomorfología Juan Carandell con tres artículos es el que destaca en un grupo constituido por tres autores. Se ha incluido en un grupo aparte, Oceanografia, a Leoncio Urabayen con un artículo sobre las corrientes marinas.

En el grupo de artículos dedicados a Geografía rural destacan Benigno Muñiz e Isidoro Reverte con tres artículos cada uno seguidos de Juan Carandell con dos. De estos ocho artículos siete llevan la palabra «etnografía» en el título, esto se debe, sin duda, a la influencia de un etnógrafo y geógrafo, Luis de Hoyos Sainz ${ }^{3}$, que dirigió 168 memorias fin de carrera en la Escuela de Estudios Supe-

2 Las iniciales M. B. pueden referirse a Modesto Bargalló, pero como también escribe en la revista Miguel Bargalló Sentís las incluimos en grupo aparte.

$3 \mathrm{El}$ profesor de Hoyos fue fundador de la Sociedad Española de Antropología, Etnografía y Prehistoria, profesor de la Escuela Superior y de la sección de Pedagogía de la Facultad de Filosofía y Letras de la Universidad Central, donde explicó cursos especiales de Etnografía y Folklore desde 1933 a 1936. 
riores del Magisterio, de las que 63 fueron estrictamente geográficas y las restantes versaron sobre temas antropométricos y etnográfi$\cos { }^{4}$.

En el grupo de Geografía regional se publicaron seis artículos, cinco sobre el concepto y método de la región geográfica, y uno de estudio regional sobre el Gironés. Pedro Chico y Miguel Santaló escribieron dos artículos cada uno, Juan Carandell escribió uno de Geografía regional comparada y Ricardo Beltrán y Rózpide otro sobre la región geográfica y el Estado político.

Destacan por su novedad dos grupos, uno sobre temas geopolíticos, el doctor Recasens y Camilo Barcia Trelles escribieron dos artículos cada uno en los que estudian la situación geopolítica de Europa y Asia, y otro P. Roselló que analiza la intervención de la Sociedad de Naciones en el conflicto polaco-lituano. El otro se dedica a estudiar la denominada «Geografía de las calamidades» en el que se recogen en forma de dos artículos una conferencia dada por Ricardo Beltrán y Rózpide, además de uno de Santaló y otro de Roselló.

Otros grupos con menos artículos son, los dedicados a estudiar la obra de geógrafos, la asistencia a Congresos y los viajes goegráficos. A Ricardo Beltrán y Rózpide le dedican dos artículos, uno Chico y otro Santaló, además este último escribió una semblanza de Jean Brhunes. En el apartado de Congresos se distinguen Carandell y Chico con uno; y en el de viajes Pedro Chico y Juan Francisco Rodríguez con un artículo cada uno.

En los artículos didácticos que versan sobre fundamentación teórica de la Didáctica de la Geografía y actualización científica de los profesores normalistas destaca Pedro Chico con ocho. En otro grupo se incluyen una serie de trabajos que recogen sugerencias didácticas, también con Pedro Chico como máximo productor, once artículos. En el tercer grupo, con 23 artículos muy distribuidos entre diferentes autores, se incluyen trabajos sobre excursiones geográficas, instrumentos fundamentales de la pedagogía activa que se proponía.

4 Datos obtenidos de Molero y del Pozo (1989), pp. 125-140. 
Estudio de las influencias en la Geografía normalista a través de las referencias bibliográficas

En el análisis de las referencias bibliográficas ${ }^{5}$, muy válido para conocer las influencias internas y externas en la Geografía normalista española, se ha seguido alguno de los criterios utilizados en los estudios bibliométricos, pero como se ha indicado anteriormente el período de tiempo cubierto, que no llega a los catorce años, impide un estudio de ese tipo. Además el estudio de las referencias bibliográficas, debido a las características de esta revista, presenta un problema, ya que en bastantes artículos no aparecen las referencias al final de los mismos o a pie de página, sino que se encuentran en el texto de donde se han extraído para su cómputo. En este caso, únicamente cuando los autores mencionados son utilizados para refrendar datos, justificar afirmaciones o proporcionar trabajos de fundamentación, se han denominado menciones y se contabilizan como referencias bibliográficas.

Un dato importante a destacar es el área de conocimiento de los autores citados. De las 283 citas contabilizadas, 205 corresponde a geógrafos $(72,4 \%$ ) seguidos muy de lejos de los naturalistas con 18 citas $(6,4 \%)$ y de los geólogos e historiadores con 14 citas (5\% cada uno de ellos), muy por debajo se citan a filósofos, poetas y escritores, políticos, militares, médicos, etc. Es decir, en las citas hay un elevado porcentaje de geógrafos, y como se comprobará más adelante cerca del $60 \%$ son extranjeros.

Los datos que se van a analizar en este apartado se refiere únicamente a 62 artículos, ya que los grupos sugerencias didácticas y excursiones con 17 y 23 artículos respectivamente han sido excluidos del cómputo porque prácticamente no llevan ninguna cita.

La primera observación que puede hacerse es la existencia de un número elevado de referencias en artículos que tiene como promedio 3,5 páginas, lo que da una media de 4,6 referencias por artículo. Es decir, se da una buena fundamentación de lo expuesto. A esto hay

5 A partir de un trabajo de T. K. Krauze y C. Hillinger en los estudios bibliométricos se distinguen con precisión entre cita, que una publicación recibe de otras posteriores y referencias, que una publicación hace de otra (López Piñero-Terrada, 1993, p. 66). 
CuAdro VII

REFERENCIAS BIBLIOGRÁFICAS POR PAÍSES

\begin{tabular}{lcr} 
Países & Número de referencias & \% \\
\hline España & 118 & 41,7 \\
Francia & 79 & 27,9 \\
Alemania & 32 & 11,3 \\
Gran Bretaña & 18 & 6,4 \\
EE. UU. & 17 & 6,0 \\
Portugal & 6 & 2,1 \\
Italia & 5 & 1,8 \\
Canadá & 4 & 1,4 \\
Suiza & 3 & 1,1 \\
Argentina & 1 & 0,3
\end{tabular}

que añadir que las citas de autores españoles suponen menos de la mitad, un $41,7 \%$ por lo que cerca del $60 \%$ de las referencias y menciones que aparecen son extranjeras, con un predominio de la Geografía francesa seguida de la alemana. A bastante distancia se sitúan Gran Bretaña y EE. UU. Estos resultados globales pueden ser matizados por los grupos temáticos. Así, por ejemplo, en los artículos sobre concepto y método de la Geografía y en los de geopolítica hay un predominio de referencias de la Geografía alemana, y más concretamente de Humboldt. En los artículos de Geomorfología la influencia es estadounidense gracias a las menciones de Davis. En cambio en Oceanografía, Geografía regional, Geografía de las calamidades, geógrafos y teoría educativa, la influencia es francesa.

El predominio francés en la Geografía normalista se explica por la permanencia en el país vecino de los mayores productores de artículos ya fueron becados por la Junta de Ampliación de Estudios e Investigaciones Científicas, este es el caso de Pedro Chico y Miguel Santaló, que son, evidentemente, los que más citas tienen en sus artículos (cuadro VIII).

El cuadro VII debe completarse con el conocimiento de los autores más citados, conocimiento que matiza las influencias internas y externas. En el cuadro IX se exponen los autores más citados y su porcentaje en relación de las citas registradas. 


\section{Cuadro VIII}

AUTORES CON MAYOR NÚMERO DE CITAS EN SUS ARTÍCULOS

\begin{tabular}{lcr} 
Autor & Número de citas & \multicolumn{1}{c}{ \% } \\
\hline Chico, Pedro & 109 & 38,5 \\
Santaló, Miguel & 86 & 30,4 \\
Muñiz, Benigno & 15 & 5,3 \\
Carandell, Juan & 13 & 4,6 \\
Dr. Recasens & 13 & 4,6 \\
Llopis, Rodolfo & 10 & 3,5 \\
Urabayen, Leoncio & 10 & 3,5 \\
San Miguel, Maximino & 8 & 2,8 \\
Beltrán y Rózpide, Ricardo & 5 & 1,8 \\
Blanco, Alberto & 5 & 1,8 \\
Reverte, Isidoro & 4 & 1,4 \\
Otros autores & 5 & 1,8
\end{tabular}

Como puede observarse, los autores que mayor influencia ejercieron en la Geografía normalista dentro del grupo de extranjeros fueron los franceses Jean Brunhes, Emmanuel Martonne, Paul Vidal de la Blache, Camille Vallaux, seguidos a bastante distancia de Ratzel, Humboldt y Ritter. El estadounidense W. M. Davis figura con trece citas todas ellas referidas a su teoría de los ciclos de erosión, siendo el mayor citador Juan Carandell, como se verá en el análisis de los enlaces bibliográficos. Los autores españoles más citados son los que presentan en su obra una fuerte influencia institucionista y regeneracionista: Ricardo Beltrán y Rózpide y Juan Dantín Cereceda.

A partir de estos datos se puede establecer una relación entre citadores y citados. Para observar este hecho se van a relacionar a los cuatro autores más citados, Brunhes, Beltrán y Rózpide, Davis y Martonne con los citadores.

De este primer acercamiento a la Geografía normalista se obtiene una serie de conclusiones, la más importante es el peso en esta revista, que en su conjunto presenta claros signos de regeneracionismo, como se ha puesto de manifiesto en otro trabajo general sobre la misma. Ha sido definida como una publicación regeneracionista normalista debido a que «condensó con rapidez las energías más valiosas de renovación normalista, y su radio de acción externa se extendió a 


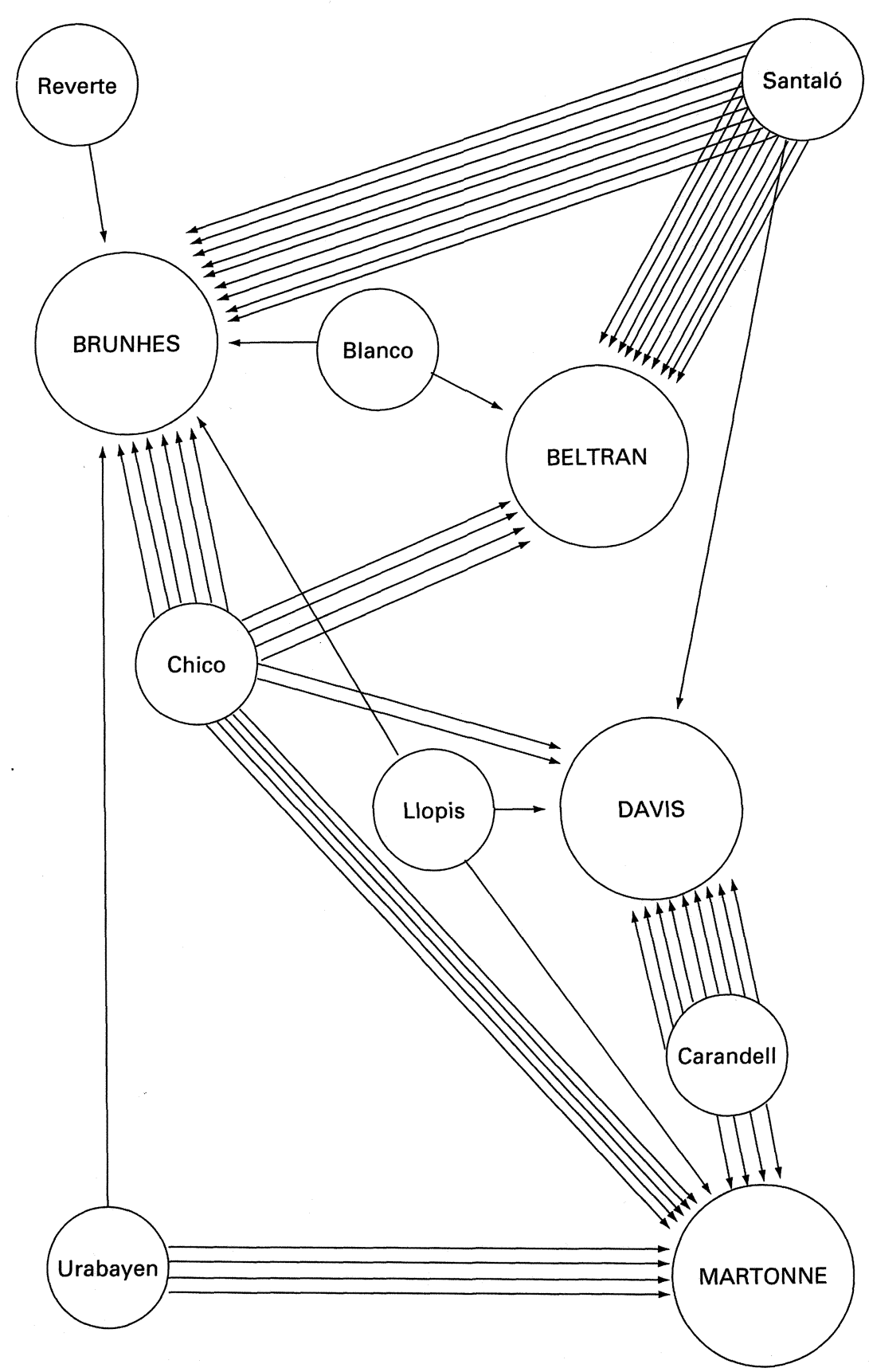

Figura 1.-Citas recibidas de los autores más representativos.

$$
-46-
$$


otros ámbitos culturales» (Díez, Del Pozo, Segura, 1988, p. 11). En este proceso, como se verá más adelante, la Geografía se presenta como una materia fundamental.

A esta característica hay que añadir las influencias extranjeras, francesa y alemana fundamentalmente, que se refleja en el análisis de las referencias bibliográficas. Estas influencias demuestran que el objetivo de este grupo de geógrafos, pertenecientes a una generación que superó la catástrofe del 98, era descubrir la raíz de la cultura española desde una perspectiva europea, de ahí la importancia que adquirieron los viajes de estudio al extranjero canalizados por la Junta para la Ampliación de Estudios e Investigaciones Científicas.

Los datos expuestos hasta aquí, que, por otra parte no son muy numerosos debido a la corta existencia de una revista multidisciplinar, deben servir de introducción para un análisis conceptual de la Geografía que se producía y consumía en dicha revista.

\section{Los geógrafos normalistas entre el determinismo y el posibilismo geográfico}

Una de las características fundamentales de la Geografía normalista es su función como instrumento de regeneración social en unos centros dedicados a la formación de maestros que evidentemente influirán directamente en la sociedad. Tal como se va a ver en las páginas siguientes al hablar de regeneracionismo y Geografía hay que aludir sin duda a esta revista y a la labor realizada por los geógrafos de estos centros y por el magisterio en general en unas décadas cruciales para la Historia de España.

Este intento de mejorar la realidad social a través de la Educación y de la Geografía supuso una actualización del concepto de esta disciplina con la introducción de la denominada Geografía moderna o científica que superaba el enciclopedismo reinante en esta materia. Luis Antón Cano en un artículo titulado Acotaciones al concepto de Geografía, habla de un cambio en las Ciencias que supone la superación del «viejo y tradicional sentido enciclopédico y absorbente con que se venía cultivando la Geografía con mengua notoria de su sentido científico» (Antón, 1924, p. 19). 
Santaló en un artículo publicado sobre La Geografía moderna: su concepto $y$ alcance establecía tres escuelas geográficas en cuanto que «participa cada una de ella en el modo de entender, según los autores, el valor jerárquico de los factores que intervienen en la definición de una región geográfica y muy en particular las relaciones entre los elementos naturales y el hombre» (Santaló, 1929, p. 223). Estas tres escuelas eran, determinista, idealista y relativista.

En la escuela determinista el representante más característico a nivel geográfico era Ratzel, en ella los elementos naturales (suelo, clima, vegetación) eran materia y causa de la actividad y desenvolvimiento humanos. Dadme un mapa de un país, llegó a decir Victor Cousin, y os diré a priori cómo será allí el hombre y el papel que dicho país representará en la historia. Ratzel afirmaba que el suelo sirve de soporte rígido a los hombres, a sus aspiraciones cambiantes y regula los destinos de los pueblos con ciega brutalidad.

En el polo opuesto se hallaba la escuela idealista, representada más que por geógrafos por filósofos e historiadores como Hegel y Febvre, sosteniendo que la humanidad escapa a la acción del medio natural por la acción del medio interno o lógico: la idea. El Mundo es la razón realizada, ha dicho el primero; cada cosa, es manifestación de un pensamiento; el suceder es el movimiento, la autoevaluación de la idea.

En la escuela relativista destacaba la figura de Vidal de la Blache. Esta escuela realizó una crítica a las obras Geografía comparada y Antropogeografía de Ritter y Ratzel respectivamente, aportando dos observaciones de gran valor. Una referente al peligro de formular generalizaciones prematuras y otra reconociendo al hombre un valor causal como agente geográfico frente al determinismo de algunas conclusiones de Ratzel. Esa labor de crítica fecunda culminó en Paul Vidal de la Blache, cuyas doctrinas orientan a todos los geógrafos franceses y se caracterizan ante todo por la tendencia de la geografía regional (Santaló, 1928, pp. 224-225).

Dentro de este panorama clarividentemente descrito por Santaló, la Geografía normalista osciló entre el determinismo y el posibilismo o relativismo geográfico, pero con una fuerte influencia de la visión orgánica de la Tierra. En el artículo mencionado se recogen las prin-

$$
-48-
$$


cipales ideas de Humboldt que se basan en la unidad de la naturaleza, que se constituye como un gran organismo. La Naturaleza, escribe Santaló citando a Humboldt, está «sometida en su conjunto al trabajo de la inteligencia es la unidad en la diversidad de fenómenos, la armonía entre las cosas creadas distintas por su forma, por su propia constitución y por las fuerzas que las animan: es el Todo, penetrado de un soplo de vida. El resultado más importante de un estudio racional de ella es llegar a esa unidad y armonía mediante el análisis de los detalles sin sucumbir bajo su masa» (Santaló, 1929, p. 220).

Por esta razón, «el intento de descomponer en sus diversos elementos la magia del mundo físico es temerario, porque el carácter capital de un paisaje y de toda escena imponente de la naturaleza, depende de la simultaneidad de ideas y de sentimientos que provoca en el observador, y su poder se revela en la conexión de impresiones y emociones que producen a un tiempo mismo» (Santaló, 1929, p. 221).

Esta visión orgánica derivó en un determinismo geográfico. Por ejemplo para Beltrán y Rózpide «debe estudiarse el globo terrestre, como un ser viviente que es, bajo el aspecto fisiológico, no meramente físico. No sólo hay fisiología vegetal y animal; hay fisiología terrestre, muy distinta de aquéllas, porque es la fisiología de un ser superior, de un mundo, en el que vegetales, animales y hombres viven como parásitos suyos». Por esto «tiene la Tierra sus propiedades orgánicas, o sea aquellas en virtud de las cuales los órganos de los seres vivos sufren la acción de los cuerpos ambientes, y se nutren de ellos, con o sin conciencia...». Esta concepción le lleva a considerar la Tierra con los caracteres propios de un cuerpo organizado, «sensibilidad, contractilidad, caloricidad y movimiento vital interno, de los que resultan las funciones fisiológicas, absorción, circulación, nutrición, secreciones, que bien ejecutadas en conjunto constituyen la vida» (Beltrán, 1928, p. 178). Debido a esta concepción, para Beltrán y Rózpide, «el valor científico de la geografía derivaba en definitiva en su propia finalidad: la determinación de leyes; pero en última instancia el objetivo de la ciencia era también de índole práctica, esto es, la aplicación del conocimiento geográfico a la solución de los problemas de distinta clase que tiene planteados el hombre para organizar su vida» (Melcón, 1989, p. 67). 
Felipe Ortega también se mostraba próximo al determinismo cuando afirmaba «que si examinamos la influencia que el medio natural ejerce sobre los españoles, observamos que éstos presentas diferencias en el modo de hablar, en la indumentaria, en las manifestaciones del culto religioso y en las maneras de construir sus casas. En el emplazamiento de las ciudades, es sobresaliente la influencia del medio. Asimismo podemos señalar variantes en las costumbres, en las distracciones, en el carácter, en las ocupaciones, en las instituciones sociales, así como diferencias culturales, jurídicas y hasta de aspecto fisiológico: es decir, de vida toda», termina afirmando «Es que el país en cierto modo nos forma» (Ortega, 1925, p. 23).

Este determinismo geográfico es matizado por el mismo Ortega poniéndolo en relación con el nivel de civilización cuando afirma que el medio «influye en el hombre tanto más cuanto menor sea su civilización. La barbarie hace al hombre esclavo de la tierra que habita, y el hombre en este estado refleja física y moralmente la influencia del país en que vive; las ciencias, las artes, las industrias, la civilización, en suma, lo libertan de dicha esclavitud»(Ortega, 1925, p. 53). No obstante, a pesar de estos matices que incluyen factores históricos y culturales en la relación entre el hombre y el medio, la influencia de este último está presente cuando habla, por ejemplo, de los patios andaluces que "con sus macetas, surtidores, columnas, caprichosos mosaicos, etc., pudiéramos con razón llamarlos patios-jardines; detalles de ornamentación que nos legaron los árabes; pero éstos al obrar así, no hacían sino reflejar la influencia del medio natural en la disposición de la vivienda. El patio y la cancela que lo separa del zaguán o portal son exigencias de los climas cálidos. Procedente de la calle atraviesa el enrejado de la cancela una corriente de aire que, después de refrescar la casa, sale al exterior por el tubo, especie de "chimenea", que forman los diferentes pisos» (Ortega, 1925, p. 136).

En esta posición entre determinismo y posibilismo se encontraba también Isidoro Reverte que afirma al estudiar la barraca murciana que en la «Antropogeografía han de considerarse, en efecto, coincidentes, en este resultado, las razones humanas y las físicas. Hay rincones en estas huertas en los que la Naturaleza lo ha puesto casi todo; hay otros, en cambio, en los que el hombre ha puesto más que la naturaleza» (Reverte, 1924, p. 305). Su posterior trayectoria estaría 
totalmente influida por la Geografía regional francesa (Cárdenas, 1987).

Beltrán y Rózpide, afirmaba que «la región natural mediante las acciones y reacciones entre la naturaleza y el Hombre se convierte en región geográfica» (1928, p. 52), enlazándose de esta forma con el posibilismo geográfico que dentro de la revista tendrá a sus máximos representantes en Miguel Santaló, Pedro Chico y Juan Carandell. El primero publicó un artículo sobre el Gironés (Santaló, 1924), resumen de una de las mejores monografías geográficas regionales publicada en 1923. Pedro Chico, en dos artículos sobre la Geografía en la Normal (1931), presenta una situación de los estudios regionales en Europa acompañada de una extensa bibliografía. Distingue las regiones naturales de las geográficas, abogando por el término de región geográfica porque abarca y supera todo criterio unilateral sea histórico, geológico, hidrográfico o administrativo.

No obstante, la definición que recoge Chico de Roxly, en la región geográfica está presente la idea de organismo: «La región natural, afirma, es un organismo integrado por diferentes elementos físicos, biológicos y humanos, con una interacción entre las condiciones físicas y biológicas; naturaleza por un lado y respuesta humana por otro (o precipitado geográfico que dice nuestro colega Urabayen).» También se observa un relativo determinismo cuando sigue la idea de Mackinder y de Herbertson que consideran la región natural «aquella demarcación terrestre en la que todos los fenómenos físicos, y éstos imprimiendo su huella sobre los humanos (el subrayado es nuestro) originan una fisonomía geográfica propia que personaliza una región diferenciándola de sus colindantes» (Chico, 1931, p. 7).

Posteriormente, en 1993, el mismo Chico sostenía que «dentro del totalismo orgánico de la Geografía cabe, siendo fieles a nuestros maestros de la Universidad y de la antigua Escuela Superior, persistir en el rumbo geográfico humano como matiz principal de nuestra laboración y significación» (Chico, 1933, p. 72). Este rumbo, la acción del hombre sobre un medio que ofrece un haz de posibilidades y que el hombre transforma en función de su nivel cultural y técnico, es el que va a hacer posible superar el determinismo geográfico, llegando a afirmarse «que a medida que se desarrollan las vías de comunica- 
ción y las ciudades adquieren importancia, la influencia inversa del hombre sobre el medio se acentúa: ello demuestra que la Geografía no es tampoco ciego determinismo» (Chico, 1931, p. 47).

Juan Carandell, catedrático de Enseñanza Media y habitual colaborador de la revista, rebate el determinismo geográfico, a pesar de su formación naturalista. En un artículo sobre Geografía humana regional comparada de las campiñas de Córdoba y León después de estudiar estos dos espacios geográficos teniendo en cuenta el encadenamiento de los postulados geológicos, topográficos fisográficos con los teoremas humanos, termina declarando el «fracaso del determinismo geográfico a rajatabla. La realidad de los hechos demostrados rebasa los postulados geográficos, cósmicos. Hay que buscar el determinismo histórico. Y entonces la luz se hace espléndida, los perfiles de la solución se cortan rotundos» (Carandell, 1930, p. 29).

Además de esta concepción de la Geografía, muy propia de la época, ya que ésta se institucionalizó en un ambiente en el que predominaban las corrientes positivas de las que los geógrafos se van separando por influencia del posibilismo geográfico, se observan una serie de innovaciones y enfoques metodológicos que se van a analizar a continuación.

Carandell introdujo novedades conceptuales y metodológicas tanto en la Geografía Física como la Humana. A nivel de Geomorfología dio a conocer, mediante ejercicios prácticos, la teoría de los ciclos de erosión de Davis. Comenta que en 1917 tenía traducidos al castellano los Practical Exercises in Physical Geography, y Elementary Physical Géograpphy, y que en 1931 no había podido publicar, razón por lo cual aprovechó las páginas de esta revista para darlos a conocer. De la primera obra ofrece unas prácticas sobre el ciclo de la erosión fluvial, cascadas, rápidos y ríos de pendiente gradual o uniforme, acompañando de nueve figuras sobre las que el alumno debía trabajar (Carandell, 1931).

En otro artículo se centra en la necesidad de extraer de las viejas cartas una serie de datos que nutran a las jóvenes ramas de la ciencia geográfica. Siguiendo al profesor Lobeck, en su libro Diagram of Europe (Wisconsin Geographical Press, Madison, Wis, 1923), elabora en este artículo un diagrama fisiográfico de la provincia de Córdoba, 
escala 1:500.000. Se distinguen dos partes. En una confecciona un diagrama en perspectiva caballera del valle medio del Guadalquivir a partir de un mapa planimétrico en el que se conservó, sobre todo, las líneas de drenaje, los ríos; sobre él se representaron los diversos relieves y su naturaleza con modalidades adecuadas del dibujo, acentuando los contrastes entre los mismos. En otra se incluye una propuesta didáctica para su realización en el aula.

Destaca la metodología empleada en su artículo Estudios de Geografía Humana. La población de la provincia de Málaga (1934), en el que relaciona con gran originalidad los aspectos fisiográficos, sociales e históricos. Introduce por primera vez en España criterios de análisis locacional. Un año antes Christaller había publicado en Alemania su teoría sobre los lugares centrales que indirectamente se recogen en este trabajo. Por ejemplo, al analizar la «pulverización» del hábitat humano en los partidos judiciales de Málaga y Vélez indica que «cuadriculándolos convenientemente resultarían una malla de 2,5 y 2,2 kilómetros cuadrados con un núcleo de casas en medio, sin contar las intermedias aisladas» (Carandell, 1934, p. 71). Cuando estudia Ronda indica que «figura con muy pocas entidades de población: 11, a las que corresponden un área de 38,9 kilómetros cuadrados, cuadrícula que supone entre núcleo y núcleo una distancia de algo más de 6,2 kilómetros. Si, por otra parte tenemos en cuenta que a cada ayuntamiento corresponde un término municipal de 74,7 kilómetros, resultará que de pueblo a pueblo hay un intervalo de $8,7 \mathrm{ki}$ lómetros» (Carandell, 1934, p. 72). Todo lo indicado hasta aquí demuestra el nivel de actualización y modernización de la que hemos denominado "Geografía normalista», en la que participaron otros profesores de diferentes niveles educativos.

Maximino San Miguel de la Cámara (1927) expuso el estado bibliográfico de las investigaciones sobre la región volcánica de Olot. Es de destacar, también, el artículo de Leoncio Urabayen (1925) sobre las corrientes marinas, debido a la precisión y actualizada bibliografía que incluye en el mismo.

Otros estudios que se introdujeron fueron los geopolíticos en una Europa que acababa de terminar una guerra y en la que se presentaban fuertes desequilibrios territoriales. Se proponía una' Europa fede- 
ral, ya que «los veintisiete Estados europeos forman una unidad orgánica, un tejido en el que es difícil separar los hilos que lo componen», pero ante esta propuesta "sobrevino en 1933 la catástrofe, el derrumbamiento espiritual de Alemania, hecho que significa un conflicto hondo entre Alemania y la cultura europea» (Recasens, 1934, p. 184). En otros dos artículos, resumen de las conferencias sobre Panasia de Camilo Barcia Trelles, se analizan las presiones sobre este continente de Rusia y Japón (Barcia, 1935).

\section{La Geografía como instrumento de regeneración nacional}

La Revista de Escuelas Normales está impregnada del espíritu regeneracionista español de la época, que puede observarse más concretamente en los artículos de tipo educativo y geográfico. La Geografía facilita el conocimiento del medio geográfico, conocimiento necesario para el desarrollo de las naciones. Esta necesidad está presente en el pensamiento de los geógrafos normalistas cuando Santaló recoge unos textos de Humboldt: «En la vida de las naciones ocurre lo mismo que en la naturaleza donde, según una feliz expresión de Goethe, en su eterna impulsión recibida o irradiada, en el desarrollo de todos los seres, no conoce el paro ni el reposo y maldice todo lo que retrasa o tiende a suspender el movimiento.

Estos peligros se alejan con el cultivo y propagación de los estudios serios y profundos. El hombre no puede actuar sobre la naturaleza más que en la medida que aprende a medirla con precisión y a conocer sus leyes. El poder de las sociedades humanas está en su inteligencia y crece o decrece con ella.

Los pueblos que no contribuyen al progreso se empobrecen de modo fatal y con tanta más rapidez cuanto mayor es el rejuvenecimiento de las fuerzas en los Estados limítrofes» (Santaló, 1929, pp. 221-222).

El medio geográfico español presentaba una serie de desajustes: entre el medio natural y los sistemas productivos, entre las regiones, y entre el hombre y el medio en una doble vertiente, médica y catastrófica. 
En este sentido, la política hidráulica regeneracionista facilitó el conocimiento geográfico, ya que supuso un intento de «encontrar una relación más equilibrada y menos desajustada entre los funcionamientos productivos y las condiciones del medio natural en que se desenvuelven» (Gómez-Ortega, 1987, p. 83). La concepción orgánica de la Tierra llevó a los geógrafos normalistas a esta preocupación; por ejemplo, Beltrán y Rózpide afirma que el agua y aire «son la sangre de la Tierra. Ser humano o animal que pierde su sangre, ser vegetal que pierde su savia, mueren; ser mundial, mundo que pierde el agua y el aire mueren también» (Beltrán, 1928, p. 177), enlazando de esta forma con los planteamientos de Lucas Mallada y Joaquín Costa que relacionaron la sequedad del suelo con la sequedad del espíritu, e incluso llegó este último a afirmar que una política hidráulica adecuada podría suponer una regeneración de la raza.

En la superación de los desajustes entre el medio geográfico y los sistemas productivos la figura del maestro rural adquiere un gran valor, ya que puede ser un instrumento para una mejor planificación de los espacios rurales. Pedro Herce ${ }^{6}$ proponía en las páginas de la revista una cooperación entre el maestro, las Normales y el progreso agrícola en el que «el ingeniero agrónomo estaría en relación directa con los maestros rurales, orientándolos en los problemas agrícolas característicos de cada zona o comarca natural de su provincia; y en justa correspondencia éstos serían los cooperadores de aquél manteniendo vivo el recuerdo de sus consejos técnicos en cada pueblo». Debido a esto «el maestro sería algo así como un agente del ingeniero agrónomo en cada pueblo, y el técnico dispondría de valiosos datos sobre cosechas, aparición de plagas, accidentes meteorológicos, etc., de incalculable valor para el mejor desempeño de su cargo, que indirectamente repercutiría en la adopción de medios conducentes al perfeccionamiento de la agricultura» (Herce, 1924, p. 111).

Pero los desajustes geográficos no son únicamente entre el medio natural y el sistema productivo y económico, sino que existen otros que son motivo de estudio por parte de los que hemos denominado «geógrafos normalistas». Los desajustes regionales los ponía de ma-

6 Pedro Herce fue ingeniero jefe del servicio agronómico de Guadalajara y posteriormente profesor de la Escuela de Ingenieros Agrónomos. 
nifiesto Miguel Santaló en 1924 al analizar «la antinomia presente entre la división político administrativa y las unidades dibujadas por la fisiografía y la población del solar ibérico». Recogiendo una opinión de Chico, expuesta en su libro El problema regional, se mostraba optimista por una inmediata y provechosa aplicación de las investigaciones del ramo científico profesional adaptadas a una reorganización regional de España. Escribía Chico, «el Directorio militar que el día 13 de septiembre de 1923, mediante un golpe de estado, asumió la responsabilidad de renovar la forma de gobierno de la nación española, formuló entre sus primeros planes el de atender a la organización de España por regiones vigorosas y fuertes que habían de tener mayor vitalidad que la absurda división de 1833» (Chico, 1924). Pero estas perspectivas no se llevaron a cabo, tal como indica Santaló, ya que «la solución anunciada, que podía ser altamente beneficiosa para los intereses nacionales, se aplaza indefinidamente. Se ha hecho pública la decisión del Directorio desistiendo del proyecto de organización regional de España, ante los conflictos que ofrecía el solventar los deseos encontrados de muchas ciudades que aspiraban a la capitalidad de las regiones» (Santaló, 1924, p. 225).

Llama la atención la relativa comprensión a las posibles medidas territoriales del Directorio militar de geógrafo de hondas convicciones democráticas, que fue ministro durante la Segunda República y sufrió exilio en Méjico después de la guerra civil, pero que estaba convencido de la necesidad de una regeneración del país. Esto pone de manifiesto «la admiración incondicionada del General Primo de Rivera y bastantes de sus adeptos hacia Costa» (Tierno, 1971, p. 371) y la posible expectación que aquel régimen causó en sus primeros momentos en las capas regeneracionistas de España.

Por estas razones los geógrafos normalistas planteaban la necesidad de potenciar los estudios regionales que iban apareciendo cada día en mayor número de libros y revistas, y esperaban una mayor acogida por parte del Estado y mayor unificación de métodos, para que se elaborase pronto una obra de conjunto sobre lo que denominaban «pequeño continente peninsular». Pero además del conocimiento del medio geográfico para evitar los desajustes productivos y regionales, aparece una línea en la Revista que intenta estudiar y evitar los desajustes entre el hombre y el medio para mejorar las condiciones 
concretas de vida. Esta línea tiene una doble perspectiva, una médica y otra referida al estudio de los riesgos y catástrofes naturales.

En relación con la primera hay que situar la publicación de una serie de Topografías médicas, muy propia de la época, a las que hace referencia Pedro Chico, y que han de ser la base para una mejora de las condiciones higiénicas. Por ello «deberá estudiarse la influencia del medio hasta en la patología, frío y poca presión, enfermedades nerviosas y congestiones, del aparato respiratorio, reumatismos, así como en otros climas las enfermedades dominantes atacaban al aparato digestivo, o prevalecer al paludismo, escrofula, etc. (Chico, 1931, p. 28). Todo esto traería una mejora de la raza, preocupación constante de los regeneracionistas. Lucas Mallada a finales del siglo había descrito a gran parte de los españoles con semblante enjuto, atezado y verdoso y talla diminuta, todo ello debido «a una alimentación deficiente, a los crudos temporales de las altas parameras, a los excesivos ardores de un sol abrasador y a los desfavorables cruces de las razas invasoras» (Mallada, 1890, p. 38).

Estas preocupaciones se recogieron en la Escuela de Estudios Superiores del Magisterio con un desarrollo de los estudios antropométricos, cuyo máximo impulsor fue Luis de Hoyos Sainz. Como se ha visto anteriormente este profesor dirigió 168 memorias fin de carrera en la citada Escuela Superior de las que 13 eran antropométricas, de diversas ciudades, entre 1910-31, aunque otras muchas hacían referencia al crecimiento y morfología de los niños españoles. Benigno Muñiz (1925) en dos artículos sobre los «vaqueiros de alzada» muestra este interés cuando dedica un apartado a los rasgos antropométricos aplicando las escalas de Topinard y Broca para medir la altura y el índice cefálico de este grupo étnico.

Desde otra perspectiva, el desajuste medio-hombre es estudiado en los artículos que hacen referencia a la Geografía de las calamidades, inquietud europea que llegó a España y que fue muy bien acogida en las Escuelas Normales. Giovanni Ciraolo propuso en 1921 la creación de un organismo permanente capaz de intervenir con eficacia para aliviar los efectos de las catástrofes que sumen en la miseria a muchas zonas del globo. Posteriormente, el comité Internacional de la Cruz Roja encargó a Mr. Raoul Montaudon, presidente de la Socie- 
dad Geográfica de Ginebra el establecimiento de una carta universal de las zonas afectadas con mayor o menor frecuencia.

Se establecen once grupos de calamidades: «terremotos, erupciones volcánicas, marejadas, fenómenos eólicos -huracanes, ciclones y tifones-, sequías, aludes, inundaciones, incendios, langosta, hambres y pestes» (Santaló, 1927, p. 294). Pero básicamente no se trata sólo de socorrer como remedio o paliativo del daño sufrido, sino de socorrer previendo, previniendo y evitando el daño. Por esta razón, la Unión Internacional de Socorro tenía como objeto «la observación y estudio de los fenómenos naturales para determinar ante todo las zonas, regiones o lugares en que se padecen, con cierta periodicidad y mayor frecuencia, las desgracias o catástrofes públicas como consecuencia de aquellos fenómenos o fuerzas naturales, con intervención, a veces, de fuerzas humanas del orden económico y social. La determinación de estas zonas, la localización en tales o cuales países de cada especie de calamidad, es el aspecto geográfico de que hablamos, cuya primera finalidad debe ser la formación del Atlas geográfico universal de calamidades naturales» (Beltrán, 1928, p. 135).

Por todo ello se proponía crear una especie de S.I.G. consistente en hacer en «cada país y para cada calamidad una lista cronológica de las catástrofes con indicación tan precisa como posible de las causas aparentes, de las regiones afectadas, de la pérdida de vidas humanas, de los daños materiales, elementos todos que permiten establecer el coeficiente de frecuencia e intensidad, y paralelamente ir dando la distribución en el espacio» (Beltrán, 1928, p. 176). A todas estas catástrofes naturales había que añadir otra, la guerra, considerada como la gran calamidad humana, debiéndose señalarse en el Atlas los países favorecidos por ella.

\section{La Geografía como via de regeneracionismo educativo}

Las dos características educativas del movimiento regeneracionista a nivel educativo se encuentran en esta revista, por un lado el valor que se da a la intuición y por otro la visión orgánica que se tiene de la Pedagogía.

$$
-58-
$$


Santaló en la selección de textos que hace de Humboldt manifiesta su formación geográfico-pedagógica, ya que recoge las páginas en las que se muestra muy claramente la influencia del pedagogo suizo Pestalozzi en el naturalista alemán, sobre todo en el concepto de intuición, que está presente cuando analiza las relaciones que se dan en la naturaleza «Es la intuición de estas relaciones lo que ensancha los horizontes del espíritu y ennoblece las emociones, como resultado de la observación, de la meditación y de la historia donde se concentran todas las direcciones del pensamiento» (Santaló, 1929, p. 220).

El concepto de intuición de Pestalozzi estaba muy presente en el grupo de pedagogos de la época, por ejemplo, para Luis Zulueta «la intuición pestalozziana no significa receptividad por los sentidos, pasiva observación, muertas lecciones de cosas. Intuir es pensar mediante la percepción de los objetos, en la percepción de los objetos. En la intuición no es el alumno como una cámara obscura que refleja los objetos exteriores, sino más bien como una linterna que proyecta sus propias ideas. Sólo en la intuición el pensamiento tiene vida. Sólo con el pensar, la intuición adquiere valor (Zulueta, 1927, p. 61). La intuición a nivel pedagógico se constituye en el eje de la educación. Giner de los Ríos exigía del discípulo que «pensase y reflexionase por sí mismo, en la medida de sus fuerzas, que investigase, arguyese, cuestionase, que dude, que despliegue las alas del espíritu, en fin que se rinda a la conciencia de su personalidad racional» (López-Morillas, 1969, p. 14). Es el método de Sócrates, remozado y ampliado en tiempos por Rousseau, Pestalozzi, Froebel.

El despliegue de las alas del espíritu, que se propugna, lleva a potencial el estudio integral del paisaje; además de su análisis científico, el paisaje se presenta como un estado psíquico en el que se intenta incorporar el cuerpo a la experiencia de los objetos. Esta idea fue definida posteriormente por el filósofo Vischer en 1872 con el término de empatía (Einfühlung), refiriéndose a ella como un sentimiento más que como un proceso mental. Vischer veía en la empatía una cualidad casi mística y hablaba de la unión emocional que se produce entre una persona y un objeto exterior, «avanzando la hipótesis de que la empatía con los objetos tiene lugar cuando proyectamos sobre ellos nuestras emociones personales» (Bloomer, 1982, p. 39). Siguiendo estas ideas se ha hablado del concepto de paisaje en- 
tre la Física y la Metafísica propio de la generación del 98 (Pena, 1983).

Esta visión del paisaje está presente en las páginas de esta revista cuando se afirma la necesidad de potenciar la emoción en la enseñanza de la Geografía y desarrollar un «sentimiento de honda emoción que funde las piedras, el color, las plantas y aun al hombre que se mueve en ellos, en una sola expresión. Coloca al espíritu en una tensión de inquietud, de movilidad, como el de algunas figuras de $\mathrm{El}$ Greco. Es la emoción del caminante capaz, que descubre desde lo alto de una cuesta un horizonte inmenso, y el paisaje infinito en aspectos y matices cábele en su retina porque es susceptible de simplicidad. La emoción, entonces, se traduce en el más bello y placentero -aun cuando arranque sudores de amargura- de los estímulos para la acción especulativa humana (Santaló, 1923, núm. 3).

Se adopta de esta forma la educación integral de la persona, científica, ética y estética. López-Morillas (1969) indica que a la noción de ser humano como «unidad orgánica» corresponde la de la ciencia como un «todo orgánico» y la de la pedagogía como sistema orgánico de diferenciación progresiva. Esta concepción orgánica determinó que en la Institución y en los ambientes influidos por ella se procediese a incorporar en sus programas primario y secundario actividades encaminadas a poner en juego esas otras facultades: la gimnasia, el dibujo, el canto, los ejercicios manuales, las cajas de ahorro, las excursiones, introduciendo además la literatura, el arte, la antropología, la geología, la tecnología y las ciencias sociales. Siguiendo estas ideas se expresaba Miguel Bargalló cuando escribió que «es una concepción menguada de la escuela primaria el creerla, exclusiva ni principalmente, de enseñanza. El maestro ha de entregar a la sociedad jóvenes aptos para profesar estudios, artes, industrias, labores de cualquier género, que exigen actividad, clarividencia, rectitud, tolerancia, distinción, hábito de obrar el bien y por último, iniciativa en el ejercicio adquisitivo de las aptitudes básicas de la lectura, escritura y cálculo» (Bargalló Sentís, 1924, p. 268).

Giner de los Ríos insiste en el carácter sintético de la enseñanza genuina, refractario a la desmembración artificial del conocimiento en «asignaturas», porque, como no se cansa de repetir, «la ciencia no 
es una serie lineal sino un organismo, todos cuyos miembros se implican y condicionan mutuamente. De aquí la conveniencia de recurrir desde un principio al procedimiento concéntrico, en que no se altera la índole de la enseñanza, sino que sólo se prolonga su radio» (López Morillas, 1969, p. 15).

La Geografía, en este procedimiento concéntrico, era básica «Todos nuestros intentos de estos últimos años se encaminan a ver el modo, traído de Decroly, de hacer la Geografía el centro fundamental de interés de la vida escolar y encajar su estudio en las enseñanzas fundamentales de la escuela. Los mejores principios, las normas mejores de la escuela activa de nuestro tiempo encajan maravillosamente en el trabajo y la enseñanza geográfica; todos los novísimos y sugestivos métodos didácticos norteamericanos, ingleses y alemanes, encuentran en la Geografía su mejor campo de acción (Chico, 1932, p. 6). Este mismo método lo propugnaba Llopis en un artículo publicado en la Revista de Pedagogía (1926) titulado «La Geografía en el método Decroly. De esta forma como ha afirmado Vilá Valentí, al referirse a la obra de Santaló como geógrafo, la Geografía se constituye como el mejor instrumento de renovación pedagógica del momento (Vilá, 1988).

Todo este proceso de educación geográfica se basaba en el método topográfico muy practicado en la Escuela de Estudios Superiores del Magisterio, introducido en España por Isidoro Antillón a principios del siglo xIx; este método proponía, como se indicó anteriormente, enseñar la Geografía partiendo de lo conocido a lo desconocido. Por ello era fundamental la enseñanza en el medio, que se conoce y experimenta a través de la observación directa que potenciada mediante paseos y excursiones. Rodolfo Llopis afirmaba, recogiendo la opinión de Mabel Barker, que «no se trata de utilizar, como hasta ahora, el estudio de la naturaleza como un medio, uno de tantos, para realizar la educación de los niños, sino como el medio por excelencia que puede formar la personalidad completa del educando. Por esta razón la región geográfica es un verdadero microcosmos, donde puede el niño hacer perfectamente su educación y su preparación humana, pues la región es la verdadera escena donde se representa el drama de la vida de sus habitantes» (Llopis, 1927, p. 339). 
Isidoro Reverte partía de que la enseñanza de la Geografía es «el estudio de la realidad en la realidad misma; del concepto de que es necesario empezar por ver para llegar a visualizar. De otra forma se podrá poseer un léxico más o menos geográfico, pero nunca el conocimiento de las formas generales fisiográficas y biogeográficas necesarias como punto de partida. Pues es tan difícil hacer comprender, sin haberlos visto lo que es el mar, el río o la montaña, como enterar a un ciego nato de los que es un color o a un sordomudo de lo que es el sonido» (Reverte, 1923, p. 134).

Por todo ello, el excursionismo, al que se dedican 23 artículos, que suponen un 22,5\% de la producción geográfica total de la revista y un $45,5 \%$ de los artículos estrictamente didácticos, se constituye como un pilar básico en la educación geográfica. Esta actividad educativa fue introducida por Rafael Torres Campos, y es una de las claves del movimiento regeneracionista educativo español. «Con los paseos, excursiones y viajes escolares se trataba, como diría Costa, de arrasar los cimientos de la antigua escuela y aventar sus escombros, de hacer de ella una sociedad en pequeño mientras no pudiese ser ésta una escuela en grande, de que no existiese más autoridad que la que mana del respeto mutuo y del mutuo aprendizaje, de que la sociedad y la naturaleza se convirtiesen en el mejor libro de texto (Rodríguez, 1990-1991, p. 226).

Entre los artículos publicados en esta revista sobre excursionismo destaca uno de Pedro Chico sobre Fuentetoba, en el que se marca un objetivo muy válido para este tipo de actividad geográfico-educativa, ya que se ha de pretender mediante ellas que «los alumnos se expresen con sencillez y claridad, ejerciten su razonamiento geográfico, dibujen con soltura los croquis en los cuadernos, amen los colores al emplear lápices o aguada en sus cuadernos, desarrollen sus músculos en la marcha durante las excursiones, valoren la belleza del campo (estos campos descritos por Machado tan acertadamente) y sientan simpatía por el suelo del macizo central español» (Chico, 1925, p. 12).

Además de la observación directa, se proponen en 17 artículos unas series de sugerencias didácticas para realizar en el aula basadas normalmente en experiencias de clase, en todas ellas está presente el principio de actividad en el proceso enseñanza-aprendizaje; en este 
grupo de artículos sigue siendo Pedro Chico el máximo productor. Sus propuestas educativas y didácticas han sido estudiadas en otro artículo (Herrero, 1993).

De todo lo expuesto hasta aquí puede concluirse que la Geografía en la Revista de Escuelas Normales tuvo una gran importancia tanto por el espacio que ocupa en la misma, analizado con criterios estadísticos, como por el significado que tuvo en una sociedad que necesitaba una profunda regeneración que se busca desde una óptica europea, de ahí la importancia que estadísticamente tienen las referencias bibliográficas de geógrafos extranjeros. La Geografía que se produce en esta revista, de claro signo regeneracionista, oscila entre el determinismo y el posibilismo geográfo, pero sobre todo tiene una función social y pedagógica muy clara, ayudar a resolver los múltiples desajustes existentes entre el medio natural y el hombre. Además se constituye, por sus características, como el mejor instrumento de renovación educativa, ya que ayuda a formar ciudadanos, en un ambiente pedagógico muy influido por la Institución Libre de Enseñanza, y en el que en palabras de Jean Sarrailh, escritas cuando se refería al óbito de Cossío, se ha de fomentar la formación de la conciencia, la honradez, la dignidad de la conducta privada y pública, la generosidad y la abnegación.

\section{BIBLIOGRAFÍA}

Antón CANo, Luis (1924): «Acotaciones al concepto actual de Geografía», Revista de Escuelas Normales, núm. 19, pp. 265-266.

Barcia Trelles, Camilo (935): «Resumen de conferencias sobre Panasia dadas por el profesor...», Revista de escuelas Normales, núm. 109, pp. 34-40.

- (1935): «Resumen de las conferencias sobre Panasia dadas por el profesor... (II)», Revista de Escuelas Normales, núm. 110, pp. 69-72.

Bargallo Sentis, Miguel (1924): "Quince días en París», Revista de Escuelas Normales, núm. 19, pp. 266-268.

BeLtRÁ Y RÓZPiDe, Ricardo (1928): «La Unión Internacional de Socorro y la Geografía de las calamidades», Revista de Escuelas Normales, núm. 53, pp. 134-136.

- (1928): «La Unión Internacional de Socorro y la Geografía de las calamidades», Revista de Escuelas Normales, núm. 54, pp. 175-178.

Bloomer, Kent C.; Moore, Charles W. (1982): Cuerpo, memoria y arquitectura. Introducción al diseño arquitectónico. Madrid, $\mathrm{H}$. Blume Ediciones.

CAPEL, Horacio (1976): La geografía española tras la guerra civil. Geocrítica. Barcelona, Ediciones de la Universidad de Barcelona. 
CARAndell, Juan (1923): «Recursos didácticos en la enseñanza de la Geografía Física. Los diagramas fisiográficos. Las perspectivas caballeras», Revista de Escuelas Normales, núm. 9, pp. 264-267.

- (1930): «Geografía humana regional y comparada de las campiñas de Córdoba y León», Revista de Escuelas Normales, núm. 69, pp. 25-30.

- (1931): «Cómo enseña Geografía el maestro William Morris Davis», Revista de Escuelas Normales, núm. 79-80, pp. 60-71.

- (1934): «Estudios de Geografía humana. La población en la provincia de Málaga», Revista de Escuelas Normales, núm. 102, pp. 66-72.

CÁrdenas, Isabel (1988): Isidoro Reverte. Valoración de su obra geográfica y pedagógica, Murcia, Academia Alfonso X el Sabio.

Costa, Joaquín (1911): Política hidráulica, edición preparada por Fernando Sáenz Ridruejo, Madrid, Colegio de Ingenieros de Caminos, Canales y Puertos, 1975.

CHIco, Pedro (1924): El problema regional, Soria.

- (1925): «Enseñanza de la Geografía. Una excursión de estudios», Revista de Escuelas Normales, núm. 21, pp. 11-19.

- (1931): «La Geografía en la Normal (I)», Revista de Escuelas Normales, núm. 83, pp. 6-11.

- (1931): «La Geografía en la Normal (II)», Revista de Escuelas Normales, núm. 84, pp. 25-29.

- (1931): «La Geografía en la Normal (III)», Revista de Escuelas Normales, núm. 85, pp. 47-50.

- (1933): «La Geografía en las Escuelas Normales nuevas (I)», Revista de Escuelas Normales, núm. 94, pp. 38-40.

- (1933): «La Geografía en las Escuelas Normales nuevas (conclusión)», Revista de Escuelas Normales, núm. 96, pp. 71-74.

Diez Torre, Alejandro; Pozo, María, y Segura, Manuel (1988): «La Revista de Escuela Normales. Una publicación de regeneración normalista nacida en Guadalajara», Revista Interuniversitaria de Formación del Profesorado, núm. 1.

GINER DE LOS Ríos, Francisco: Ensayos, selección, edición y prólogo de Juan López-Morillas, Madrid, Alianza Editorial, pp. 77-89.

Gómez Mendoza, Josefina; Ortega Cantero, Nicolás (1987): «Geografía y regeneracionismo», Sistema, núm. 77, pp. 77-89.

HeRce, Pedro (1924): «La cooperación del maestro y de las Normales en el progreso agrícola», Revista de Escuelas Normales, núm. 14, pp. 110-111.

HerRero Fabregat, Clemente (1989): «La Didáctica de la Geografía en las Escuelas Universitarias de Magisterio, Boletín de la Asociación de Geógrafos Españoles, núm. 8.

- (1993): «Pedro Chico Rello y la renovación de la enseñanza de la Geografía en el primer tercio del siglo XX», Estudios Geográficos, núm. 211.

López Piñero, José M. ${ }^{a}$; Terrada, M. ${ }^{a}$ Luz (1993): La información cientifica en medicina y sus fuentes. Valencia, Instituto de Estudios Documentales e Históricos sobre la Ciencia (Universidad de Valencia-C.S.I.C.).

LLOPIs, Rodolfo (1927): «Monografía geográfica», Revista de Escuelas Normales, núm. 49, pp. 339-340.

MALLADA, Lucas (1890): Los males de la patria y la futura revolución española, edición preparada por Francisco Flores, Madrid, Alianza Editorial, 1969. 
Melcón, Julia (1989): La enseñanza de la Geografia y el profesorado de las Escuelas Normales (1882-1915), Barcelona, Publicaciones de la Universidad.

MéridÁNicolich, Eloisa (1983), Índice de la Revista de Pedagogía (1922-1936), Pamplona, Ediciones de la Universidad de Navarra, S. A.

Molero Pintado, Antonio; Pozo, M. del Mar, editores (1989): Una precedente histórico enla Formación Universitaria del Profesorado Español: Escuela de Estudios Superiores del Magisterio (1902-1932), Alcalá de Henares, Universidad de Alcalá de Henares, Departamento de Educación.

MuÑIZ, Benigno (1925): «Contribución al estudio de la Etnografía regional. Los vaqueiros de alzada I», Revista de Escuelas Normales, núm. 25, mayo, pp. 165-170.

- (1925): «Contribución al estudio de la Etnografía regional. Los vaqueiros de alzada II», Revista de Escuelas Normales, núm. 26, pp. 202-204.

OrTEGA, Felipe (1925): «Lección de Geografía. Hechos geográficos: el medio natural y el hombre español I», Revista de Escuelas Normales, núm. 22, pp. 53-55.

- (1925): «Lección de Geografía: Hechos geográficos: el medio natural y el hombre español II», Revista de Escuelas Normales, núm. 24, pp. 136-137.

Pena, María del Carmen (1983): Pintura de paisaje e ideología. La generación del 98, Madrid, Taurus Ediciones, S. A.

RECasens, Dr. (1934): «Pan-Europa. Resumen de las conferencias del Dr. Recasens», Revista de Escuelas Normales, núm. 105, pp. 181-184.

- (1934): «Pan-Europa. Resumen de las conferencias del Dr. Recasens», XII, Revista de Escuelas Normales, núm. 106, pp. 214-217.

Reverte, Isidoro (1923): «Dificultades en la enseñanza de la Geografía I», Revista de Escuelas Normales, núm. 5, pp. 134-136.

- (1923): «Dificultades en la enseñanza de la Geografía II», Revista de Escuelas Normales, núm. 9, pp. 267-269.

- (1924): «Contribución a la etnografía regional. La barraca murciana», Revista de Escuelas Normales, núm. 20, pp. 305-307.

Rodriguez Esteban, José Antonio (1990-1991): «Rafael Torres Campos y el excursionismo geográfico», Boletín de la Real Sociedad Geográfica, tomo CXXVI-CXXVII.

San Miguel de la Camara, Maximino (1927): «Las investigaciones de la región volcánica de Olot», Revista de Escuelas Normales, núm. 48, pp. 290-291.

Santaló, Miguel (1923): «La emoción en la enseñanza de la Geografía», Revista de Escuelas Normales, núm. 3, pp. 67-69.

- (1924): «La tradición geográfica hispánica y los estudios regionales», Revista de Escuelas Normales, núms. 17-18, pp. 225-226.

- (1924): «Regiones y comarcas geográficas. El Gironés», Revista de Escuelas Normales, núm. 19, pp. 271-275.

- (1927): «Geografía y Filantropía. Distribución de las grandes calamidades públicas, Revista de Escuelas Normales, núm. 48, pp. 293-294.

- (1929): «La Geografía moderna, su concepto y alcance». Revista de Escuelas Normales, núm. 66, pp. 219-225.

Sarrailh, M. Jean (1936), «In memoriam. La España nueva. Manuel B. Cossío», Boletín de la Institución Libre de Enseñanza, tomo LX.

Tierno Galván, Leoncio (1925): «Agua, fuego, tierra y aire», Revista de Escuelas Normales, núm. 23, pp. 85-89.

Vila VALENTI, J. (1988): «Miquel Santaló, geógrafo», Revista de Girona, núm. 127, pp. 136-141.

Zulueta, Luis (1927): «Pestalozzi, fundador de la escuela popular», Revista de Pedagogía, núm. 62, pp. 59-64. 